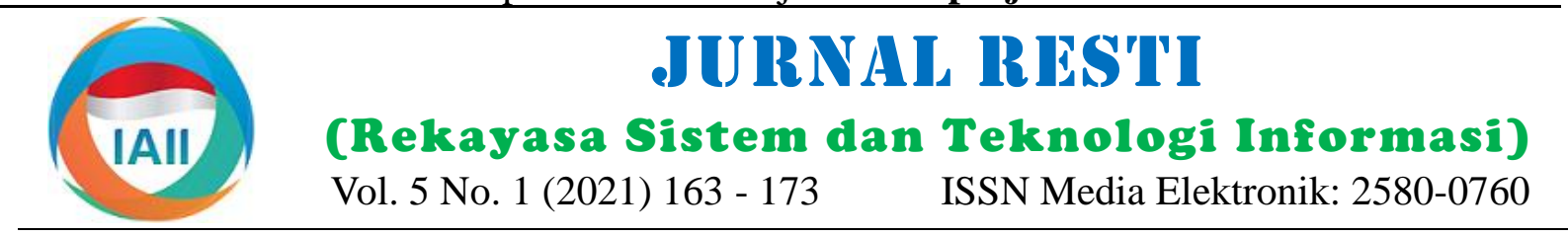

\title{
Pabrikasi Unit Kontrol Berbasis Web pada Smarthome System untuk Pengoperasian Pintu Gerbang
}

\author{
Lucky Hardian $^{1}$, Arief Goeritno ${ }^{2}$ \\ ${ }^{1}$ PT Elangperdana Tyre Industry, Jalan Elang, Desa Sukahati, Kecamatan Citeureup, Kabupaten Bogor 16810 \\ ${ }^{2}$ Program Studi Teknik Elektro, Fakultas Teknik dan Sains, Universitas Ibn Khaldun Bogor \\ 11uckyhardian19@gmail.com, ${ }^{2}$ arief.goeritno@uika-bogor.ac.id*
}

\begin{abstract}
A control unit based-on web in smarthome system has been designed and constructed. The control unit can be integrated into the smarthome system platform for gate operation via a smartphone. The research objectives, namely (i) integration of hardware and availability of raw files for applications, (ii) programming for control unit, and (iii) availability of control unit and implementation of validation tests. The result of integration is a form of successful hardware handshaking. The programming result is a form of successful software handshaking, including (i) a flowchart-based algorithm, while the syntax structure is based on the Arduino IDE, (ii) the comfiling and uploading stages of the syntax structure to the Arduino UNO R3 module, including the process online control based on RemoteXY version 4.5.1 via a web browser, and (iii) uploading files from personal computers and smartphones based on Android. The availability of the control unit physical building for the validation test process is the achievement of handshaking in hardware and software, in the form of performance measurement of the control unit with 3 (three) kinds of observations, namely (i) "open", (ii) "close”, or (iii) lock/unlock state. In general, it is concluded that the web-based control unit on the smarthome system for gate operation can function and perform according to plan.
\end{abstract}

Keywords: adaptive control, embedded software, module of Arduino UNO R3, nodeMCU ESP8266, wireless application protocol.

\begin{abstract}
Abstrak
Telah dirancang dan dipabrikasi sebuah unit kontrol berbasis web pada sistem smarthome. Unit kontrol tersebut dapat diintegrasikan ke platform sistem smarthome untuk pengoperasian pintu gerbang melalui smartphone. Sasaran penelitian ini, yaitu (i) pengintegrasian perangkat keras dan ketersediaan file mentah untuk aplikasi, (ii) pemrograman untuk unit kontrol, dan (iii) ketersediaan unitr kontrol dan pelaksanaan uji validasi. Hasil integrasi merupakan bentuk keberhasilan rantai jabat-tangan secara perangkat keras. Hasil pemrograman merupakan bentuk keberhasilan rantai jabat-tangan secara perangkat lunak, meliputi (i) algoritma berbasis diagram alir, sedangkan struktur sintaks berbasis kepada Arduino IDE, (ii) tahapan comfiling dan pengunggahan struktur sintaks ke modul Arduino UNO R3, termasuk proses pengontrolan berbasis RemoteXY versi 4.5.1 secara online melalui web browser, dan (iii) pengunggahan file dari komputer personal dan smartphone berbasis Android. Ketersediaan bangunan fisis unit control untuk proses uji validasi merupakan ketercapaian rantai jabat-tangan secara perangkat keras dan lunak, berupa pengukuran kinerja terhadap unit kontrol dengan 3 (tiga) macam pengamatan, yaitu (i) "membuka", (ii) "menutup", atau (iii) keadaan lock/unlock. Secara umum disimpulkan, bahwa unit kontrol berbasis web pada smarthome system untuk pengoperasian pintu gerbang dapat berfungsi dan berkinerja sesuai perencanaan.
\end{abstract}

Kata kunci: kontrol adaptif, aplikasi tertanam, modul Arduino UNO R3, nodeMCU ESP8266, protokol aplikasi nirkabel.

\section{Pendahuluan}

Keberadaan sistem smarthome (rumah pintar) dimaknai sebagai bentuk pemberian segala kenyamanan, keselamatan, keamanan, dan penghematan energi yang terkendali dan berlangsung secara otomatis dan terprogram $[1,2]$. Pemanfaatan instrumentasi elektronis untuk otomasi, dapat dikontrol melalui komputer personal $(P C)$ [3] atau pemroses mikro terpabrikasi dalam bentuk modul yang berbasis chips mikrokontroler [4-12]. Pemanfaatan pemroses mikro dapat berupa Programmable Logic Controller (PLC) untuk sistem otomasi yang kokoh (robust) [13, 14], maupun berupa 
mikrokontroler yang termanfaatkan secara umum untuk peralatan elektronika dalam bentuk embedded system berbagai keperluan dalam bentuk prototype atau untuk sistem pengendalian jarak jauh berbasis miniature sebuah sistem [15-23]. Berdasarkan berbagai gelombang radio. Keberadaan Wi-Fi yang merupakan hal itu, peranan peranti elektronika berupa sistem $P L C$ teknologi untuk saling bertukar data melalui penggunaan maupun modul mikrokontroler tersebut telah menjadi gelombang radio (secara nirkabel) dan berbantuan suatu keniscayaan sebagai bagian penting pada sistem modul komunikasi Wi-Fi berbantuan smartphone otomasi secara realtime pada sistem smarthome [1,2, berbasis Android yang digunakan sebagai pengendali 24].

Sistem smarthome terdiri atas sejumlah subsistem untuk Pengintegrasian terhadap sejumlah modul elektronika sejumlah pengontrolan peralatan elektronika yang hanya dan penanaman (embedding) perangkat lunak (software, dilakukan melalui satu pengontrol pusat [24, 1, 2]. aplikasi) Integrated Development Environment (IDE) Keberadaan semua peralatan elektronika dapat dari Arduino atau Arduino IDE untuk keterbentukan terkendali secara otomatis dengan jarak tertentu, sebuah sistem tertanam (embedded system) telah termasuk di dalamnya sistem pengkondisian udara (air menjadi suatu keniscayaan [19-21]. Arduino IDE [34conditioning) dalam ruangan, pesawat televisi, home 38] untuk aplikasi pemantauan berbasis app inventor theatre, microwave, lampu penerangan, dan pada komputer personal dan smartphone berbasis pengoperasian pintu gerbang [24]. Pengendalian Android [18, 26, 27], merupakan bentuk keberhasilan terhadap hampir semua perlengkapan dan peralatan dalam rantai jabat-tangan (handshaking) secara listrik, dapat dilakukan melalui perintah berupa suara perangkat keras (hardware) dan perangkat (software) [9], sinar inframerah [10, 11], atau kendali jarak-jauh dengan sejumlah tahapan. Proses pengunduhan file (remote) [18, 20, 22, 25-27], sehingga pengaturan tata Arduino IDE melalui web www.arduino.cc dan proses lampu hingga ke berbagai peralatan pada gedung atau ekstraksi merupakan tahapan awal, dimana aplikasi rumah tinggal terpusatkan pada sistem smarthome [24, tersebut dapat digunakan untuk sejumlah keperluan. 1, 2]. Sebelum rumah atau gedung mulai dilakukan Tahapan setelah Arduino IDE terpasang di $P C$, pembangunan, penentuan terhadap peralatan elektronika dilakukan langkah lanjutan berupa penentuan algoritma harus direncanakan dan dipertimbangkan [24]. dan penyusunan struktur sintaks yang dilanjutkan Perencanaan dengan pengikutsertaan teknologi dengan proses compiling dan uploading terhadap source smarthome harus dimulai dengan pengaturan kabel- code dari komputer personal (personal computer, PC) ke kabel elektronika pada tahap pembangunan.

Pengoperasian pintu gerbang secara otomatis merupakan salah satu alat bantu untuk kondisi tertentu, sangat diperlukan oleh pengguna mobil untuk efisiensi waktu, tenaga, kenyamanan, dan keamanan. Teknik kendali jarak jauh di sisi lain, saat ini telah berkembang sangat pesat diberbagai bidang yang berbasis kepada mikrokontroler (pengontrol mikro) [28], maupun sistem elektronis berbantuan komputer personal [2, 25]. Pemanfaatan teknik kendali jarak jauh berbantuan
smartphone berbasis Android dan jaringan wireless berbasis protokol Internet, digunakan untuk pengoperasian pintu gerbang [26, 27, 29-31]. Perangkat smarthome. Perbedaan dengan penelitian sebelumnya, elektronik tersebut haruslah berada dalam sebuah titik terletak pada mekanisme pemanfaatan sistem akses (hotspot) jaringan nirkabel, agar dapat terhubung komunikasi yang digunakan. Penelitian sebelumnya ke cakupan Wi-Fi. Dalam suatu jaringan Wi-Fi [27], dengan akses jaringan Internet secara keseluruhan, baik biasanya titik akses dengan jangkauan hingga 20 meter smartphone maupun unit kontrol pada smarthome di dalam ruangan, dan terdapat pula jangkauan lebih jauh system, sehingga diperoleh kontribusi penelitian berupa untuk cakupan Wi-Fi di luar ruangan.

Keterhubungan sebuah perangkat elektronika ke jaringan Internet, dapat digunakan jaringan $\mathrm{Wi}-\mathrm{Fi}[26$, 27]. Keberadaan jaringan $W i-F i$ dengan penggunaan frekuensi gelombang radio pada rentang $2,4 \mathrm{GHz}$. sampai $5 \mathrm{GHz}$., telah menjadi sebuah protokol [29, 27] untuk pengaksesan. dapat dilakukan melalui jaringan Internet atau Wi-Fi Keberhasilan dalam keterhubungan pada jaringan, merupakan bentuk handshaking secara hardware dan software. Kondisi handshaking tersebut merupakan suatu keniscayaan terhadap integrasi diintegrasikan ke platform sistem

dalam mikrokontroler Arduino UNO R3 [34-38]. Pembuatan struktur sintaks untuk sistem pengendalian berbasis teknik kendali jarak jauh (remote control), merupakan tahapan pengunduhan sintaks pada Arduino untuk pengaktifan modul Ethernet Shield maupun $\mathrm{Wi}-\mathrm{Fi}$ Router [18, 26, 27].

Berdasarkan sejumlah penjelasan tersebut, maka dirancang-bangun sebuah unit kontrol pada sistem smarthome dalam bentuk sebuah sistem tertanam berbasis modul Arduino UNO R3 dan NodeMCU ESP8266 untuk keperluan pengoperasian pintu gerbang penyederhanaan penggunaan perangkat atau modul elektronika. Hal tersebut terkait dengan peniadaan modul elektronika untuk akses ke Internet secara langsung yang digantikan oleh penggunaan modul NodeMCU untuk akses Internet melalui jaringan Wi-Fi setempat (local), sehingga tidak diperlukan kondisi smartphone harus terhubung ke jaringan Internet secara langsung, cukup dengan jarak 10 sampai 15 meter dari pintu gerbang tertuju di mana unit kontrol ditempatkan, agar pengoperasian pintu gerbang dapat dilakukan melalui smartphone. Diagram skematis unit kontrol 
yang terintegrasi dengan smarthome system, seperti ditunjukkan pada Gambar 1.

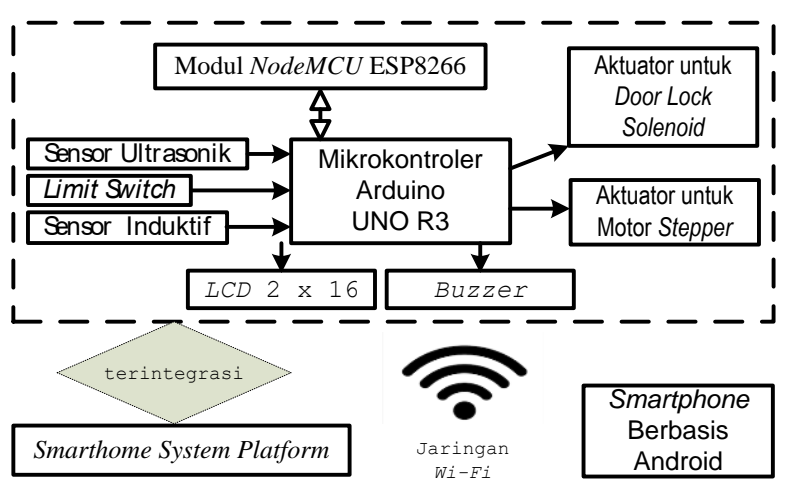

Gambar 1. Diagram skematis unit kontrol yang terintegrasi dengan smarthome system

Berdasarkan Gambar 1 dapat ditetapkan sasaran penelitian ini, yaitu (a) mengintegrasikan sejumlah modul elektronika, (b) memrogram untuk sistem tertanam, dan (c) memperoleh bangunan fisis dan hasil uji validasi pengukuran kinerja sistem tertanam untuk pengoperasian pintu gerbang.

\section{Metode Penelitian}

Bahan penelitian untuk pembuatan unit kontrol pada sistem smarthome yang difungsikan sebagai sistem tertanam untuk pengoperasian pintu gerbang melalui smartphone berbasis Android melalui jaringan $\mathrm{Wi}-\mathrm{Fi}$ [18, 27, 29, 32, 33], meliputi modul Arduino UNO R3 [28, 20, 21, 39], modul NodeMCU ESP8266 dengan chips ESP-01 [33], sensor jarak ultrasonik HC-SR04, sensor proximity, motor stepper, liquid crystal display (LCD) 2x16, door lock solenoid, limit switch, dan catu daya (power supply) $12 \mathrm{Vdc}$. Perangkat lunak untuk keperluan penelitian ini, meliputi Arduino IDE versi 1.8.9 dan RemoteXY versi 4.5.1 [40].

Metode penelitian berbentuk diagram alir, seperti ditunjukkan pada Gambar 2.

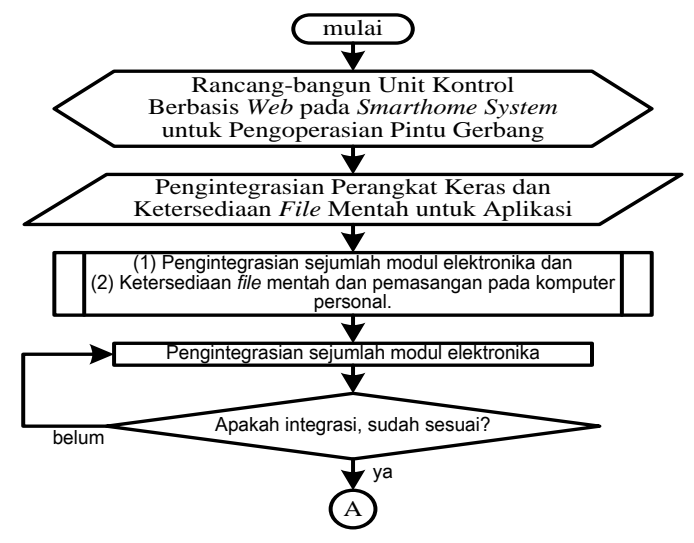

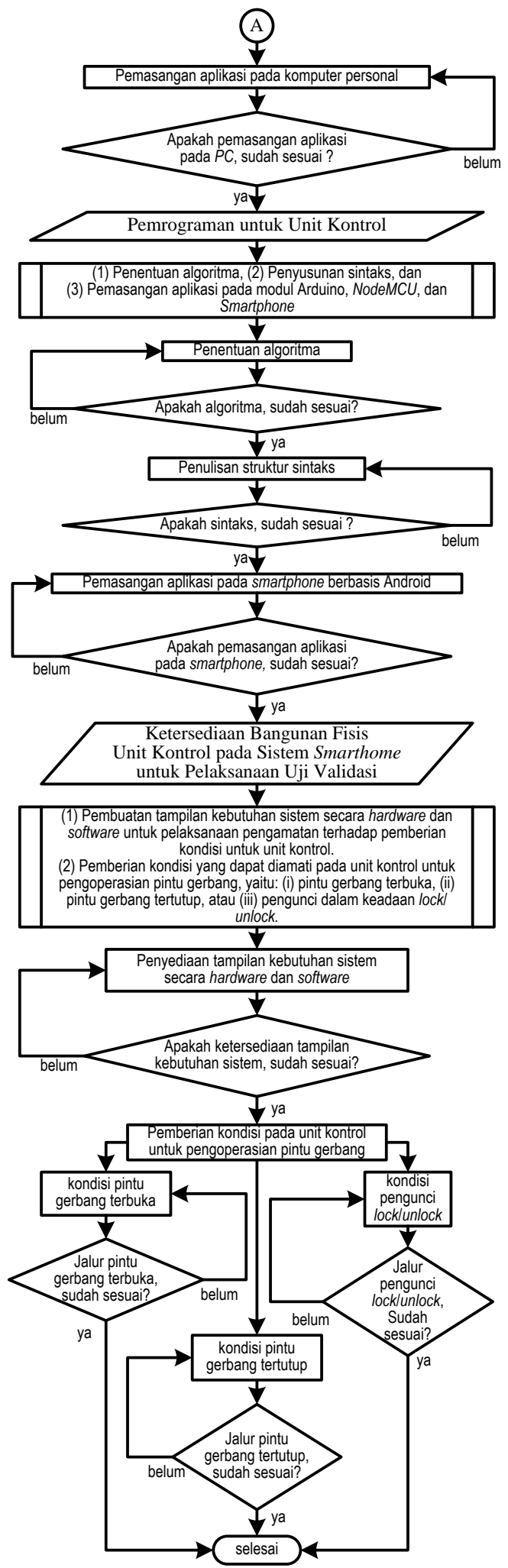

Gambar 2. Metode penelitian berbentuk diagram alir

Ditunjukkan pada Gambar 2, terdapat sejumlah tahapan untuk pencapaian setiap sasaran penelitian. 
Berkenaan dengan pelaksanaan pengintegrasian diperlukan, agar dapat digunakan untuk proses perangkat keras dan ketersediaan file mentah untuk pengamatan terhadap pemberian kondisi terhadap unit aplikasi terhadap unit kontrol pengoperasian pintu control secara langsung dan realtime. Pelaksanaan gerbang, dilakukan melalui tahapan (i) konstruksi fisis pengamatan dengan kondisi yang dapat diamati, pintu gerbang, (ii) pemilihan dan penempatan sensor, meliputi (i) proses pembukaan intu gerbang, (ii) proses dan (iii) penempatan sejumlah modul elektronika dan penutupan pintu gerbang, atau (iii) mekanisme pengawatan (wiring) terintegrasi. Pemasangan aplikasi, penguncian saat terjadi keadaan lock/unlock, sehingga berupa tahapan pengunduhan file mentah aplikasi dan keberadaan sistem sudah beroperasi atau belum dapat ekstraksi file pada komputer personal untuk modul diketahui.

Arduino UNO R3 dan NodeMCU.

Pemrograman terhadap modul Arduino UNO R3,

NodeMCU ESP8266, dan tampilan pada smartphone 3.1. Integrasi Perangkat Keras dan Ketersediaan File dilakukan dengan tahapan penentuan algoritma dalam Mentah

berbentuk diagram alir dan penyusunan struktur sintaks sesuai Arduino IDE yang berbasis bahasa $C$ atau $\mathrm{C}++$ dan diikuti fungsi-fungsi operasi dari sistem yang diinginkan. Hasil penulisan struktur sintaks berupa file berbasis Arduino UNO R3, dikirim dari komputer personal ke modul Arduino UNO R3 dan NodeMCU ESP8266. Aplikasi RemoteXY ditanamkan ke smartphone berbasis Android berupa tahapan keterhubungan dengan penyedia aplikasi berbasis RemoteXY versi 4.5.1 melalui web browser secara online pada komputer personal untuk pembuatan aplikasi pengoperasian pintu gerbang melalui smartphone melalui jaringan $\mathrm{Wi}-\mathrm{Fi}$.

Ketersediaan unit kontrol pada sistem smarthome untuk proses uji validasi dilakukan melalui ketercapaian sebuah bangunan fisis berupa sistem tertanam yang difungsikan sebagai unit kontrol pada sistem smarthome untuk mekanisme pengoperasian pintu gerbang terkendali melalui smartphone berbasis Android yang berbantuan jaringan Wi-Fi. Penjelasan tentang kebutuhan sistem hardware dan software mutlak

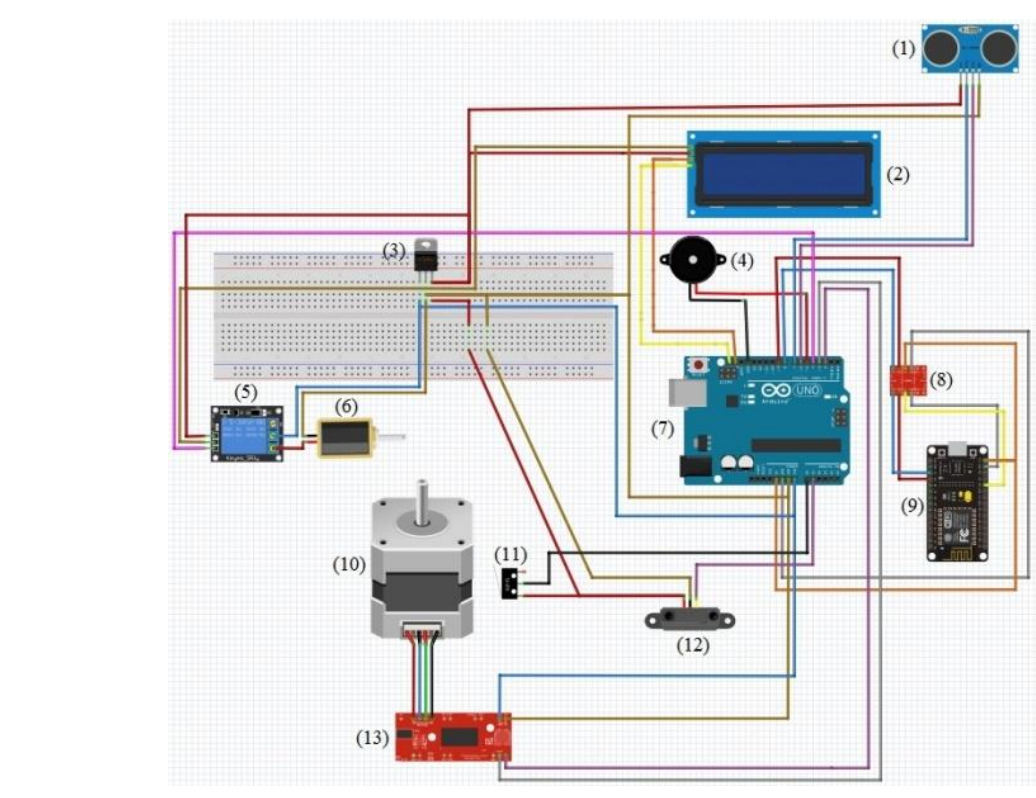

Integrasi sejumlah modul elektronika dan subsistem pendukung untuk keterbentukan fisis unit kontrol berbentuk sistem tertanam, merupakan upaya untuk ketercapaian handshaking secara hardaware, melalui pengawatan (wiring) antar pin yang bersesuaian yang dijelaskan dalam sejumlah tabel. Keterhubungan antar pin dijelaskan untuk (i) modul Arduino dan NodeMCU, (ii) modul Arduino dan motor stepper, (iii) modul Arduino dan $L C D$ 2x16, (iv) modul Arduino, IC-7805, modul relai, dan door lock solenoid, (v) modul Arduino dan sensor ultrasonik HC-SR04, (vi) modul Arduino, limit switch, dan proximity switch, dan (vii) modul Arduino dan buzzer .

Tampilan integrasi dan pengawatan antar modul elektronika, seperti ditunjukkan pada Gambar 3. Penjelasan tentang keterhubungan antar pin didasarkan kepada Gambar 3. Hubungan antar pin sejumlah modul elektronika dan subsistem pendukung, seperti ditunjukkan pada Tabel 1.

Keterangan:

(1) Sensor Ultrasonik HC-SR04

(2) $L C D 2 \times 16$

(3) IC-7805, regulator tegangan

(4) Buzzer

(5) Relai dengan koil $5 \mathrm{Vdc}$

(6) Door Lock Solenoid

(7) Modul Arduino UNO R3

(8) Logic Converter

(9) NodeMCU ESP8266

(10) Motor Stepper

(11) Limit Switch

(12) Sensor Proximity

(13) Modul Motor Stepper

Gambar 3. Tampilan integrasi dan pengawatan antar modul elektronika 
Jurnal RESTI (Rekayasa Sistem dan Teknologi Informasi) Vol. 5 No. 1 (2021) 163 - 173

\begin{tabular}{|c|c|c|c|c|c|c|c|c|c|c|c|}
\hline $\begin{array}{c}\text { Pin di } \\
\text { Modul } \\
\text { Arduino }\end{array}$ & $\begin{array}{l}\text { Pin di Modul } \\
\text { logic level } \\
\text { converter }\end{array}$ & $\begin{array}{c}\text { Pin di } \\
\text { Modul } \\
\text { NodeMCU }\end{array}$ & $\begin{array}{l}\text { Pin di } \\
\text { Motor } \\
\text { stepper }\end{array}$ & $\begin{array}{l}\text { Pin di } I C \text { - } \\
\quad 7805\end{array}$ & $\begin{array}{l}\text { Pin di } \\
L C D \\
2 \times 16\end{array}$ & $\begin{array}{c}\text { Pin di } \\
\text { modul } \\
\text { relai }\end{array}$ & $\begin{array}{l}\text { Pin di door } \\
\text { lock solenoid }\end{array}$ & $\begin{array}{c}\text { Pin di sensor } \\
\text { ultrasonik } \\
\text { HC-SR04 }\end{array}$ & $\begin{array}{c}\text { Pin di } \\
\text { limit } \\
\text { switch }\end{array}$ & $\begin{array}{c}\text { Pin } \mathrm{di} \\
\text { proximity } \\
\text { switch }\end{array}$ & $\begin{array}{l}\text { Pin di } \\
\text { Buzzer }\end{array}$ \\
\hline $5 \mathrm{~V}$ & HV/LV & Vin/3V3 & - & - & - & - & - & - & - & - & - \\
\hline GND & GND & GND & GND & GND & - & GND & GND & - & - & - & GND \\
\hline Vin & - & - & M+ & In & - & $\mathrm{COM}$ & - & - & - & - & - \\
\hline 2 & - & - & DIR & - & - & - & - & - & - & - & - \\
\hline 3 & - & - & STEP & - & - & - & - & - & - & - & - \\
\hline- & - & - & - & Out & VCC & VCC & - & VCC & $\mathrm{COM}$ & VCC & - \\
\hline (I2C) SCL & - & - & - & - & SCL & - & - & - & - & - & - \\
\hline (I2C) SDA & - & - & - & - & SDA & - & - & - & - & - & - \\
\hline 4 & - & - & - & - & - & In & - & - & - & - & - \\
\hline- & - & - & - & - & - & NO & VCC & - & - & - & - \\
\hline 5 & - & - & - & - & - & - & - & - & - & - & $(+)$ \\
\hline 6 & - & - & - & - & - & - & - & Echo & - & - & - \\
\hline 7 & - & - & - & - & - & - & - & Trigger & - & - & - \\
\hline A0 & - & - & - & - & - & - & - & - & NO & - & - \\
\hline A1 & - & - & - & - & - & - & - & - & - & IN & - \\
\hline 8 & HV1/LV1 & $\mathrm{TX}$ & - & - & - & - & - & - & - & - & - \\
\hline 9 & HV2/LV2 & $\mathrm{RX}$ & - & - & - & - & - & - & - & - & - \\
\hline
\end{tabular}

Ketersediaan file mentah untuk aplikasi dilakukan melalui pengunduhan berupa file mentah Arduino IDE versi 1.8.9 melalui web (www.arduino.cc) yang digunakan untuk proses compiling dan uploading sistem pengoperasian kondisi buka-tutup pintu gerbang. Tampilan setelah pengunduhan file mentah versi 1.8.9 dan pemasangan Arduino IDE pada komputer personal. Aplikasi berbasis Remote $X Y$ terhubung secara online ke https://remotexy.com/en/editor/ untuk dibuat dan disusun pada komputer personal untuk pembuatan sistem pengoperasian konsisi buka-tutup pintu gerbang. Pembuatan aplikasi dilakukan dengan layar design dan blocks pada komputer personal.

3.2. Aplikasi untuk Unit Kontrol pada Sistem Smarthome

Tahapan setelah software Arduino terpasang pada $P C$, maka langkah-langkah lanjutan berupa penentuan algoritma dan penulisan sintaks yang dilanjutkan dengan proses compiling dan uploading terhadap source code dari komputer personal ke dalam modul-modul (Arduino UNO R3 dan NodeMCU ESP8266). Penyusunan struktur sintaks berbasis Arduino IDE versi 1.8.9 untuk sistem pengoperasian kondisi buka-tutup pintu gerbang Gambar 4 merupakan penjelasan, bahwa diagram alir berupa tahapan pengunggahan sintaks pada Arduino tersebut berkenaan dengan permintaan pengalamatan IP UNO R3 dan NodeMCU ESP8266, sedangkan struktur dan penetapan Wi-Fi pada NodeMCU ESP8266. Untuk sintaks berbasis RemoteXY versi 4.5.1 untuk tampilan kondisi dimana modul NodeMCU ESP8266 dapat proses pengoerasian pada smartphone berbasis Android.

Setelah ditentukan algoritma berbentuk diagram alir, maka dilanjutkan dengan penyusunan struktur sintaks program berbasis Arduino IDE. Penyusunan struktur sintaks merupakan upaya untuk perolehan sejumlah Setelah penyelesaian susunan struktur sintaks untuk source code sebagai pokok pengoperasian modul pengaktifan Wi-Fi, maka diperlukan compiling pada Arduino UNO R3. Hasil perakitan sebuah unit kontrol modul Arduino IDE yang telah berisi script pengaktifan. dengan source code berbasis Arduino IDE, merupakan Tampilan penentuan algoritma untuk pengoperasian bentuk sistem tertanam (embedded system). Pengaktifan pintu gerbang, seperti ditunjukkan pada Gambar 5.

NodeMCU ESP8266 dan penyusunan struktur sintaks berbentuk diagram alir, seperti ditunjukkan pada Gambar 4.

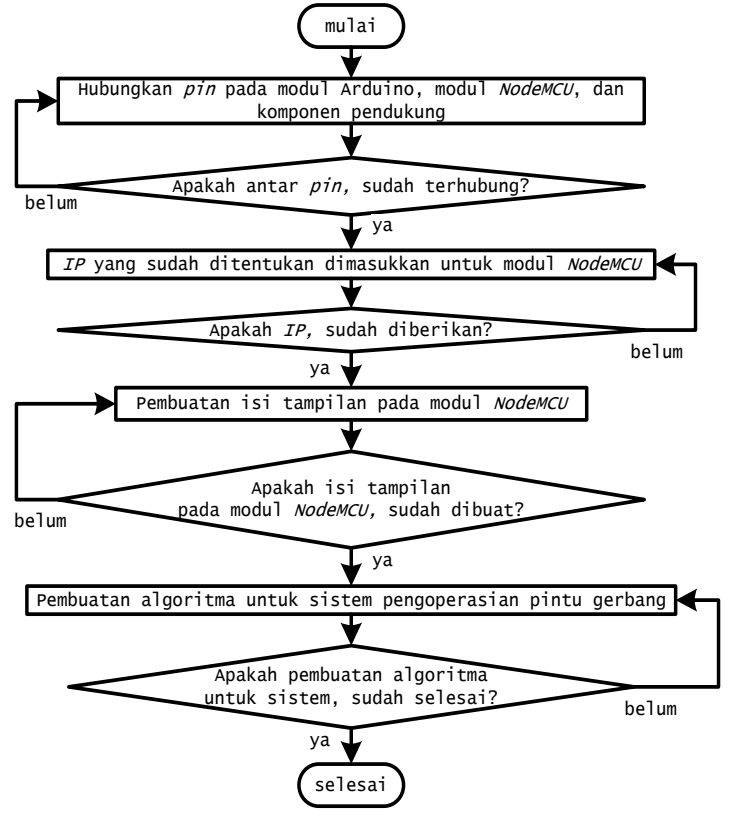

Gambar 4. Pengaktifan NodeMCU ESP8266 dan penyusunan sintaks program berbentuk diagram alir

baik, maka IP tertampilkan pada monitor Arduino IDE, tetapi jika kondisi modul NodeMCU ESP8266 terdapat masalah, maka tertampilkan error. 


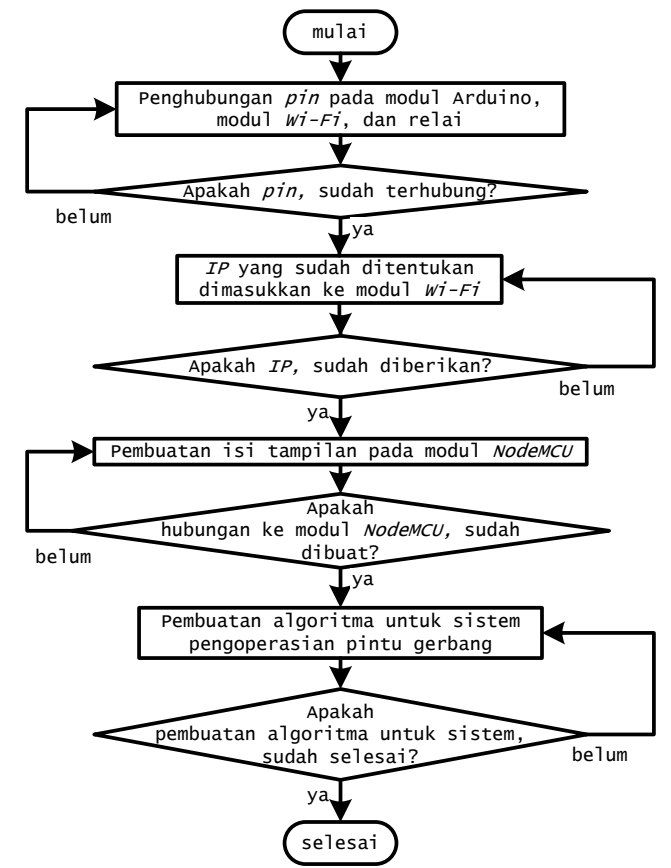

Gambar 5. Tampilan penentuan algoritma untuk pengoperasian pintu gerbang

Berdasarkan Gambar 5 dapat dijelaskan, bahwa beberapa pin telah diaktifkan, termasuk pengaktifan $I P$ yang sudah diberikan oleh NodeMCU ESP8266, dan tampilan NodeMCU ESP8266 diaktifkan melalui modul Arduino IDE yang digunakan pada sistem pengoperasian pintu gerbang.

Pembuatan struktur sintaks dalam pemrograman untuk sistem pengoperasian pintu gerbang terhadap modul Arduino UNO R3 maupun NodeMCU ESP8266 disesuaikan terhadap proses algoritma pada sebuah sistem tertanam tertunjukkan, bahwa terdapat tahapan konfigurasi pin, deklarasi sejumlah variabel, tahapan inisialisasi, struktur program utama (dengan kemunculan tampilan), proses ambil dan kirim data, dan tampilan keluaran. Tahapan compiling maupun uploading terhadap source code ke modul Arduino UNO R3 dan NodeMCU ESP8266 merupakan tahapan pasca penetapan algoritma dan penyusunan struktur sintaks program, sehingga diperoleh sejumlah source code. Proses compiling maupun uploading terhadap source code ke dalam modul Arduino UNO R3 dan NodeMCU ESP8266 dari $P C$ berbantuan kabel USB.

Pembuatan aplikasi tampilan pengoperasian pada smartphone dilakukan secara online melalui web browser (https://remotexy.com/en/). Struktur aplikasi berekstensi (.apk) yang sebelumnya telah di-"build" melalui website RemoteXY yang secara otomatis tersimpan pada $P C$ dan sudah siap untuk dipasang pada keras untuk unit kontrol, seperti ditunjukkan pada smartphone. Pembuatan aplikasi pemantauan melalui Gambar 7.

RemoteXY dilakukan melalui layar design dan blocks pada komputer personal. Tampilan hasil pembuatan aplikasi pemantauan melalui RemoteXY, seperti ditunjukkan pada Gambar 6.

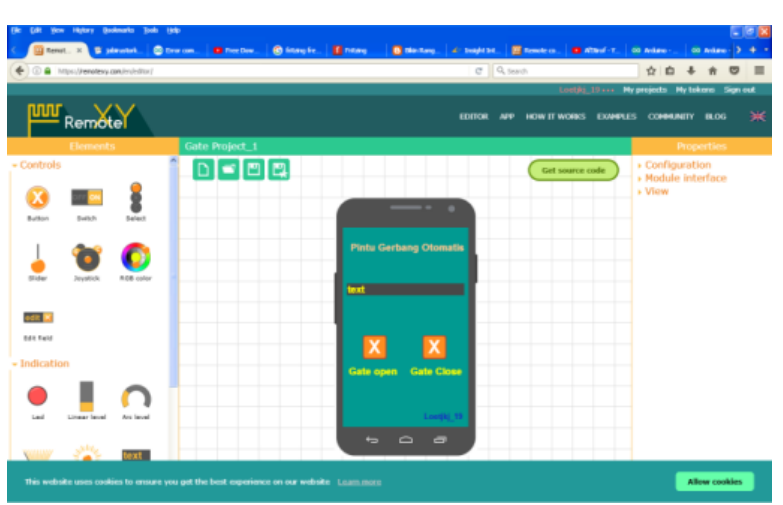

Gambar 6. Tampilan hasil pembuatan aplikasi pemantauan melalui RemoteXY

Berdasarkan Gambar 6 dapat dijelaskan, bahwa tampilan dengan layar blocks pada komputer personal dapat dilakukan untuk pemakaian, melalui langkah-langkah:

\#1) ketika aplikasi RemoteXY di-"buka", maka tertampilkan hasil dari web browser;

\#2) pada layar blocks dilakukan penentuan elements berupa tombol-tombol, indikator, dan label untuk ditampilkan pada layar smartphone, selain itu penentuan properties berupa configuration, module interface, dan view sebagai komunikasi Wi-Fi smartphone dengan modul NodeMCU ESP8266, kemudian diperoleh sumber kode dengan peng-klik-an "get source code"; \#3) source code yang telah diperoleh dari pembuatan aplikasi monitoring melalui Remote $X Y$ dapat disalin dan diunggah ke dalam Arduino IDE dan modul NodeMCU ESP8266; dan

\#4) pada layar smartphone ditampilkan hasil dari web browser berupa tombol-tombol dan indikator, maka (i) tombol-tombol dan indikator tersebut berfungsi sebagai pengoperasian pintu gerbang, (ii) text string digunakan sebagai indikator terhadap keadaan gerbang dan (iii) tombol "Gate open" dan "gate Close" digunakan sebagai button untuk pengoperasian pintu gerbang.

3.3. Ketersediaan Unit Kontrol melalui Pengintegrasian Sistem dan Uji Validasi

Kebutuhan sistem untuk pengamatan pada langkah lanjutan pada pemantauan saat pengoperasian pintu gerbang, yaitu tampilan kebutuhan sistem untuk hardware dan software, sedangkan uji validasi merupakan pengukuran kinerja sistem, meliputi tiga kondisi pengamatan.

Kebutuhan sistem meliputi hardware dan software yang dijelaskan sesuai peran dan fungsi masing-masing.

\#a) Kebutuhan sistem perangkat keras

Diagram blok tampilan kebutuhan terhadap perangkat

Berdasarkan Gambar 7 ditunjukkan, bahwa bread board digunakan untuk sistem hardware berbantuan kabel jumper secukupnya dengan tujuan, untuk kemudahan 
proses penghubungan komponen satu dengan yang lain Edition 32-Bit. Pengaksesan terhadap web dengan kabel jumper, sehingga diperoleh kemudahan https://remotexy.com/en/ digunakan sebuah browser dalam proses pelepasan saat terjadi kesalahan teknis atau Google Chrome dengan versi 83.0.4103.106, sedangkan trouble. Smartphone berbasis Android yang digunakan untuk keterhubungan dengan jaringan Wi-Fi digunakan untuk penelitian ini, yaitu ASUS Zenfone 3 Max, RAM NodeMCU ESP8266.

2 GB, Android versi 7.0 Nougat.

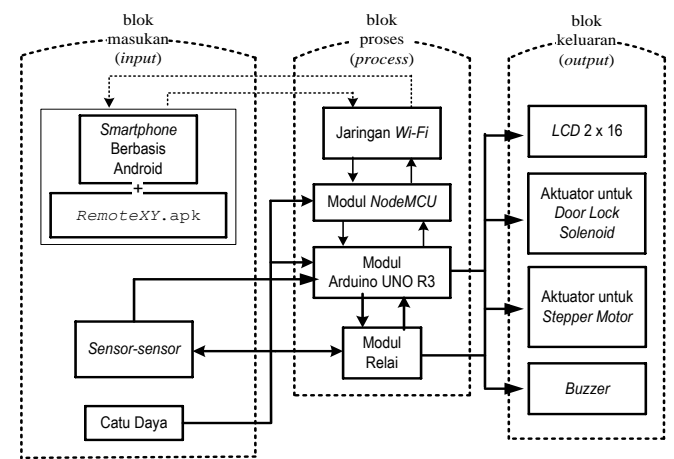

Gambar 7. Diagram blok tampilan kebutuhan terhadap perangkat keras untuk unit kontrol

Keberadaan block diagram pada sistem hardware berupa tiga blok, yaitu blok masukan, blok proses, dan blok keluaran. Blok masukan terdiri atas 4 jalur, yaitu i) untuk smartphone berbasis Android, ii) untuk aplikasi RemoteXY.apk saat pengoperasian pintu gerbang, iii) untuk sensor-sensor saat pemberian masukan (input) atau perintah pada modul Arduino UNO R3, dan iv) untuk power supply pada modul Arduino UNO R3 dan sensor-sensor. Blok proses meliputi 4 proses, yaitu i) proses untuk jaringan $W i-F i$ digunakan, agar smartphone berbasis Android dapat terhubung dengan modul NodeMCU ESP8266, ii) proses untuk modul NodeMCU ESP8266 digunakan, agar modul dapat terhubung ke jaringan $W i-F i$, iii) untuk proses pada modul Arduino UNO R3, sebagai perangkat utama pada sistem yang digunakan untuk compiling maupun uploading, agar sistem beroperasi secara sempurna, dan iv) untuk proses pada modul relai sebagai perangkat pendukung, agar modul Arduino dapat kendalikan pengoperasian pintu gerbang. Blok keluaran berupa 4 jalur keluaran, yaitu i) jalur untuk $L C D 2$ x 16 sebagai penampil kondisi buka atau tutup dari pintu gerbang, ii) jalur untuk aktuator saat door lock solenoid digunakan, untuk penguncian pintu gerbang, iii) jalur untuk aktuator saat stepper motor sebagai penggerak pintu gerbang, dan iv) jalur untuk buzzer sebagai pemberitahu kondisi, objek. apabila terdapat objek penghalang pergerakan pintu \#i) Pemantauan dan pengendalian terhadap kondisi gerbang.

Berdasarkan Gambar 8 dapat dijelaskan, bahwa perangkat lunak yang digunakan pada smartphone berbasis Android dirancang melalui web, yaitu https://remotexy.com/en/. Aplikasi pada web tersebut dikhususkan untuk pengembangan dan pembuatan aplikasi berbasis Android. Dalam pembuatan aplikasi tersebut, digunakan sebuah laptop dengan processor Core2Duos T6600, CPU 2.00GHz., dan RAM 2GB dengan sistem pengoperasian Windows XP Home \#b) Kebutuhan sistem perangkat lunak

Diagram blok tampilan kebutuhan aplikasi untuk unit kontrol, seperti ditunjukkan pada Gambar 8.

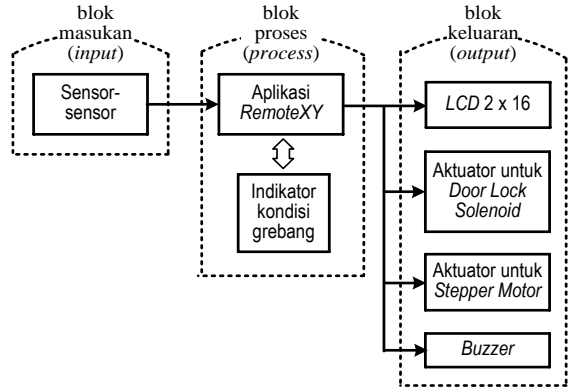

Gambar 8. Diagram blok tampilan kebutuhan aplikasi untuk unit kontrol

Sistem perangkat lunak berupa 3 diagram blok diagram, yaitu 1) blok input, 2) blok process, dan 3) blok output. Blok input terdapat satu masukan, yaitu sensor-sensor yang digunakan untuk memberikan masukan (input) atau perintah kepada modul NodeMCU ESP8266 melalui modul Arduino UNO R3 dengan aplikasi RemoteXY. Blok process sistem software ini berupa tampilan hasil modul NodeMCU ESP8266 pada aplikasi Remote $X Y$ dengan tampilan tabel, yaitu baris "indikator kondisi gerbang" berfungsi sebagai suatu informasi sistem pengamatan terhadap pengoperasian pintu gerbang. Blok output mempunyai empat keluaran, yaitu (i) $L C D 2 \times 16$ digunakan, untuk tampilan kondisi buka atau tutup pintu gerbang, (ii) aktuator untuk door lock solenoid digunakan, untuk penguncian pintu gerbang, (iii) aktuator untuk stepper motor digunakan, untuk penggerakan pintu gerbang, dan (iv) buzzer untuk pemberitahuan, apabila terdapat objek sebagai penghalang gerakan pintu gerbang.

Setelah perolehan tampilan kebutuhan sistem, dilakukan pengamatan dengan pemberian kondisi untuk pemantauan dan pengoperasian pintu gerbang, yaitu untuk kondisi pintu gerbang terbuka atau kondisi pintu gerbang tertutup atau kondisi pendeteksian keberadaan "Membuka Gerbang"

Tampilan hasil pemantauan dan pengoperasian terhadap kondisi pintu gerbang "proses membuka", seperti ditunjukkan pada Tabel 2.

Berdasarkan Tabel 2 ditunjukkan, bahwa saat tombol gate open pada smartphone ditekan, maka door lock solenoid berubah menjadi unlock, motor stepper beroperasi untuk penggerakan pintu gerbang untuk kondisi buka, dan indikator kondisi pada smartphone dan $L C D$ 2x16, "membuka gerbang". 
Tabel 2. Tampilan hasil pemantauan dan pengendalian terhadap kondisi pintu gerbang saat proses "Membuka Gerbang"

\begin{tabular}{ccccc}
\hline Pengamatan & Tampilan di smartphone & Kondisi pintu gerbang \\
\hline $\begin{array}{c}\text { Hasil tombol } \\
\text { gate open saat } \\
\text { ditekan melalui } \\
\text { smartphone }\end{array}$ & $\mathrm{X} \quad \mathrm{X}$ & \\
\hline
\end{tabular}

Saat pintu gerbang terbuka lebar sampai limit switch ON, menjadi "gerbang terbuka". Tampilan hasil pemantauan maka motor stepper berhenti beroperasi dan indikator terhadap kondisi "Gerbang Terbuka", seperti kondisi pada smartphone dan LCD 2x16 berubah ditunjukkan pada Tabel 3.

Tabel 3. Tampilan hasil pemantauan terhadap kondisi "Gerbang Terbuka"

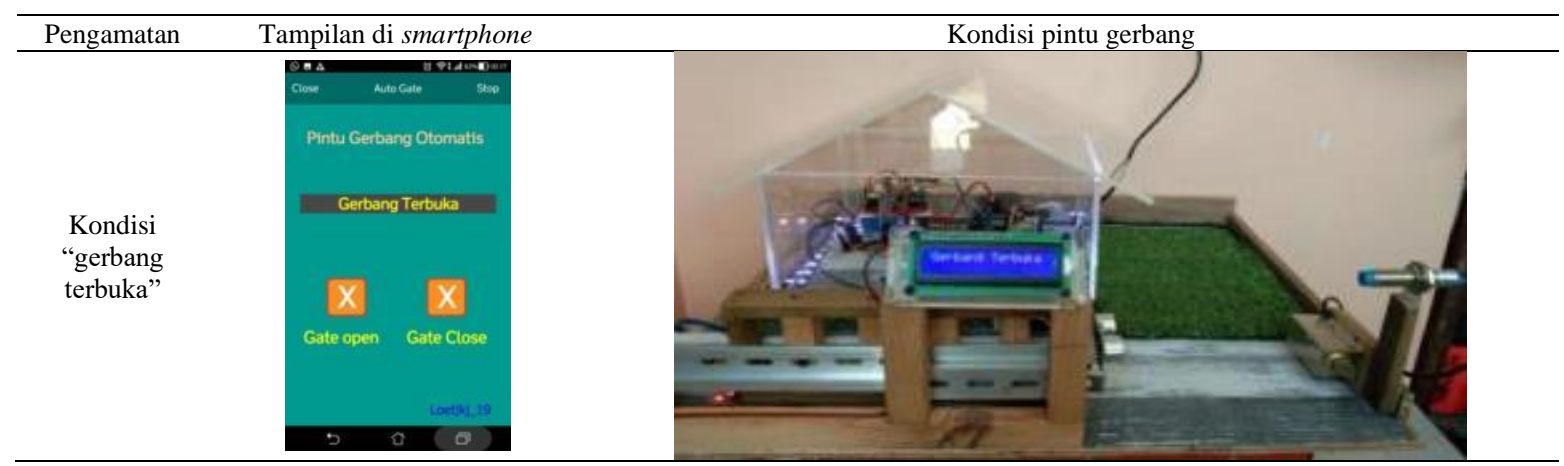

\#ii) Pemantauan dan pengendalian terhadap kondisi indikator kondisi pada smartphone dan LCD 2x16, "Menutup Gerbang"

"Menutup Gerbang". Saat pintu gerbang tertutup rapat Tampilan hasil pemantauan dan pengendalian terhadap sampai sensor proximity ON, maka motor stepper kondisi pintu gerbang saat proses "Menutup Gerbang", berhenti beroperasi, solenoid door lock berubah menjadi seperti ditunjukkan pada Tabel 4. Penjelasan untuk lock, dan indikator kondisi pada smartphone dan LCD Tabel 4, yaitu saat tombol gate close pada smartphone 2x16, "Gerbang Tertutup". Tampilan hasil pemantauan ditekan, maka motor stepper beroperasi untuk terhadap kondisi "Gerbang Tertutup", seperti penggerakan pintu gerbang untuk kondisi tutup, dan ditunjukkan pada Tabel 5.

Tabel 4. Tampilan hasil pemantauan dan pengendalian terhadap kondisi pintu gerbang saat proses "Menutup Gerbang"

\begin{tabular}{cccc}
\hline Pengamatan & Tampilan di smartphone & Kondisi pintu gerbang \\
\hline $\begin{array}{c}\text { Hasil tombol } \\
\text { gate close saat } \\
\text { ditekan melalui } \\
\text { smartphone }\end{array}$ & Pintu Gerbang Otomatis & $\mathrm{X} \quad \mathrm{X}$ \\
Gate open Gate close
\end{tabular}


Tabel 5. Tampilan hasil pemantauan terhadap kondisi "Gerbang Tertutup"

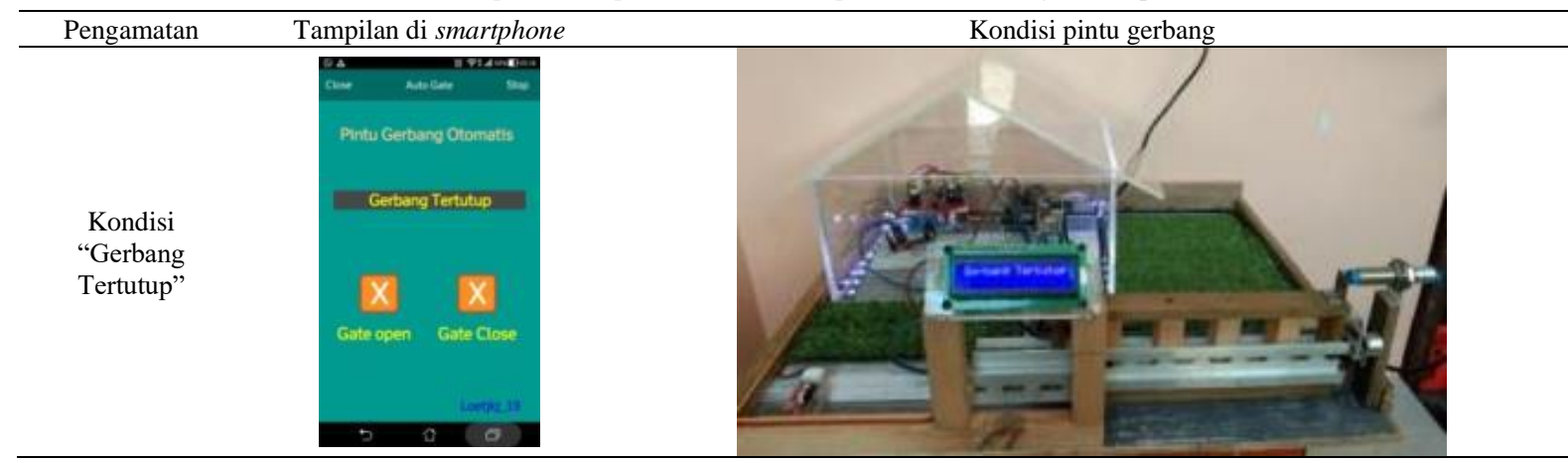

\#iii) Pemantauan dan pengendalian terhadap kondisi untuk proses tutup. Untuk keperluan pengamanan, saat "Mendeteksi ada objek" terdapat objek penghalang dalam jarak 2 sentimeter, Hasil pemantauan saat pengoperasian terhadap kondisi maka sensor jarak ultrasonik tipe HC-SR04 kirim deteksi keberadaan objek saat proses "Mendeteksi ada perintah ke motor stepper untuk berhenti beroperasi, objek" dijelaskan dengan uraian, bahwa saat tombol buzzer berbunyi, dan indikator kondisi pada smartphone "Gate Close" pada smartphone ditekan, maka motor dan LCD 2x16 dengan tampilan "Mendeteksi ada stepper beroperasi untuk penggerakan pintu gerbang objek" dan motor stepper diperintahkan untuk buka untuk penutupan. Proses berlanjut dengan indikasi pintu gerbang kembali sampai terbuka lebar dan sensor kondisi pada smartphone dan LCD 2x16, "Menutup limit switch terkondisikan ON. Tampilan hasil Gerbang”. Saat pintu gerbang "proses menutup" sensor pemantauan saat pengoperasian terhadap kondisi jarak ultrasonik tipe HC-SR04 aktif untuk pendeteksian "Mendeteksi ada objek", seperti ditunjukkan pada Tabel keberadaan objek sebagai penghalang pintu gerbang 6 .

Tabel 6. Tampilan hasil pemantauan saat pengoperasian terhadap kondisi "Mendeteksi ada objek"

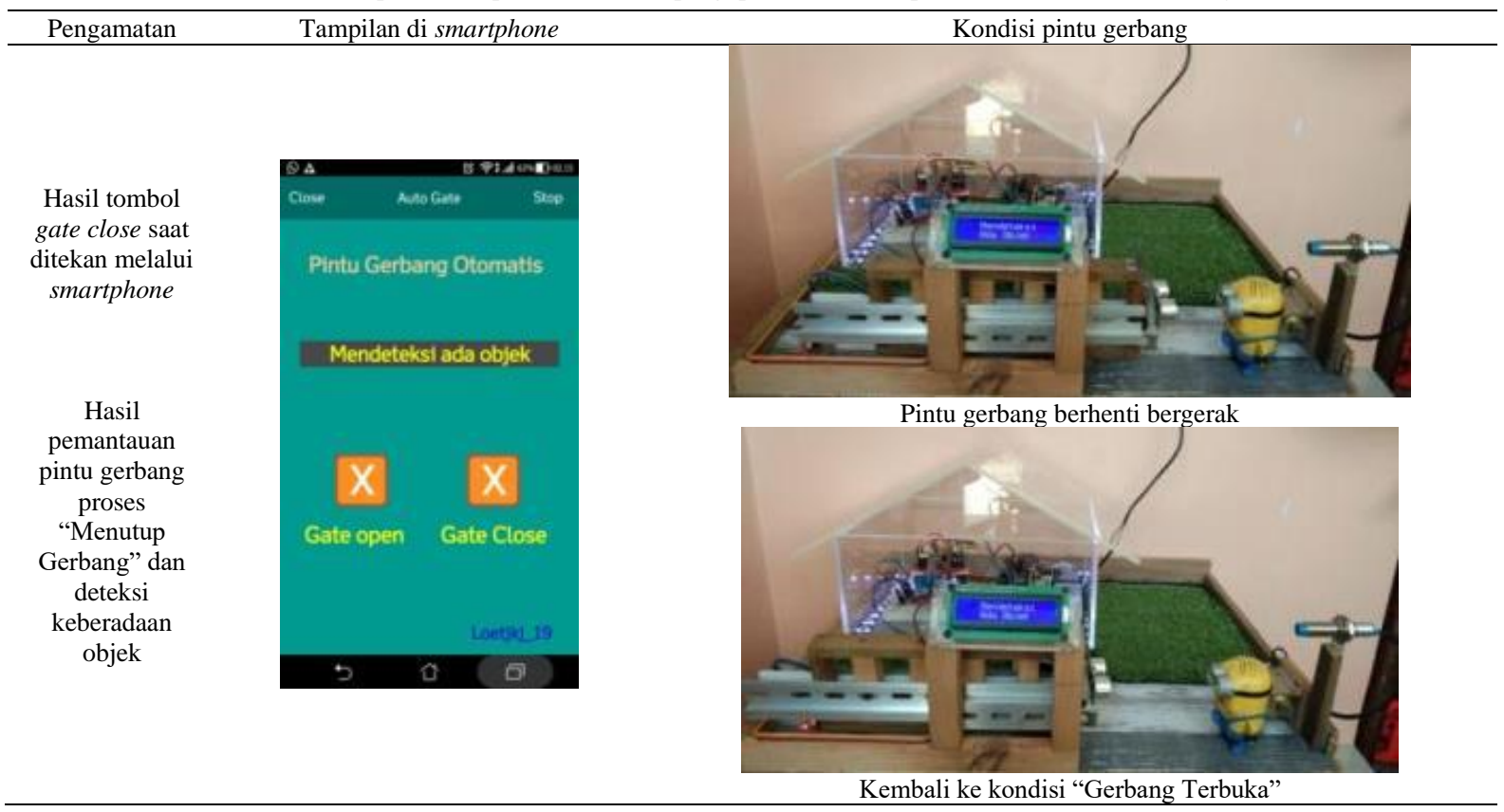

\#iv) Kinerja pada pemantauan dan pengendalian

terbuka dan dioperasikan melalui smartphone agar Hasil evaluasi terhadap unit kontrol berbasis web pada tertutup, maka pintu gerbang tertutup sesuai dengan smarthome system yang telah buat, diperoleh hasil sesuai fungsionalisasi software. Demikian halnya dengan dengan yang direncanakan (diinginkan) berdasarkan pengkondisian saat gerbang terbuka dan dioperasikan fungsionalisasi software. Saat pintu gerbang tertutup melalui smartphone agar tertutup dan pada saat gerbang dan dioperasikan melalui smartphone agar terbuka, menutup ada objek yang menghalangi gerbang, maka maka pintu gerbang terbuka sesuai dengan sensor ultrasonik akan mendeteksi objek tersebut dan fungsionalisasi software. Saat kondisi pintu gerbang memberi perintah kepada gerbang agar membuka 
gerbang kembali seperti semula, dalam keadaan terbuka. Tingkat kepresisian sensor dalam pendeteksi keberadaan objek penghalang, deteksi sensor mampu dengan jarak sebesar $2 \mathrm{~cm}$ untuk sebuah miniatur bangunan dengan skala 1:200.

\section{Kesimpulan}

Kesimpulan ditarik sesuai sasaran penelitian yang didasarkan kepada hasil dan pembahasan. Pengintegrasian terhadap perangkat keras untuk keterwujudan sebuah prototipe sistem pengoperasian pintu gerbang yang dapat dilakukan melalui smartphone berbasis Android yang berbantuan sejumlah perangkat elektronika dan jaringan $\mathrm{Wi}-\mathrm{Fi}$ dan berpedoman kepada pengawatan terintegrasi, agar diperoleh ketercapaian handshaking secara hardware. Ketersediaan file mentah digunakan untuk pembuatan struktur sintaks program untuk pengaktifan modul Arduino UNO R3 dan NodeMCU ESP8266 berupa file mentah Arduino IDE versi 1.8.9 melalui web (www.arduino.cc).

Pemrograman modul elektronika didasarkan kepada algoritma berbasis diagram alir, sedangkan penyusunan struktur sintaks berbasis Arduino IDE versi 1.8.9 untuk sistem pengoperasian pintu gerbang berupa tahapan pengunggahan sintaks pada Arduino UNO R3 dan NodeMCU ESP8266, sedangkan struktur sintaks berbasis RemoteXY versi 4.5.1 untuk tampilan proses pengoerasian pada smartphone berbasis Android yang dilakukan secara online melalui web browser (https://remotexy.com/en/) pada komputer personal dengan layar design dan blocks. Aplikasi dengan ekstensi (.apk) yang telah di-“build”, secara otomatis tersimpan pada $P C$ dan sudah siap untuk dipasang pada smartphone berbasis Android.

Pengintegrasian perangkat keras dan lunak untuk kebutuhan sistem tertanam berupa keberadaan diagram blok sistem hardware maupun software yang terdiri atas tiga blok, yaitu (1) blok masukan, (2) blok proses, dan (3) blok keluaran. Berdasarkan ketersediaan sistem tertanam secara menyeluruh, maka pelaksanaan uji validasi dengan 3 keadaan pengamatan saat "membuka, "menutup", dan terdapat lock/unlock yang teramati secara langsung dan realtime berkaitan dengan fungsionalisasi dan penunjukan kinerja unit control berbasis web.

\section{Daftar Rujukan}

[1] Ghabar, O., Lu, J., 2014. The Designing and Implementation of a Smart Home System with Wireless Sensor/Actuator and Smartphone. In: Proceedings of the INFOCOMP 2014, The Fourth International Conference on Advanced Communications and Computation, Paris, July 20-24, IARIA (The International Academy, Research, and Industry Association) XPS (Xpert Publishing Services) Press: Wilmington, DE 19803, USA.

[2] Hsu, Y-L., Chou, P-H., Chang, H-C., Lin, S-L., Yang, S-C., Su, HY., Chang, C-C., Cheng, Y-S., Kuo, Y-C, 2017. Design and Implementation of a Smart Home System Using Multisensor
Data Fusion Technology. Sensors, 17(07), pp.1-21. https://doi.org/10.3390/s17071631

[3] Goeritno, A., Herutama, Y., 2018. Prototipe Sistem Elektronis Berbantuan PC untuk Pemantauan Kondisi Pasokan Daya Listrik. Jurnal Rekayasa Elektrika, 14(2), pp.96-104. http://dx.doi.org/10.17529/jre.v14i2.10904

[4] Nugroho, D.J., Goeritno, A., Muhidin, 2014. Prototipe Sistem Akuisisi dan Kontrol Berbasis Mikrokontroler untuk Studi Eksperimental Pengontrolan Suhu dan Kelembaban Relatif pada Analogi Rak Komputer Server. In: FORTEI, Seminar Forum Pendidikan Tinggi Teknik Elektro Indonesia 2014, Bandung, 2 Juni 2014, ITB: Bandung.

5] Effendi, R., Goeritno, A., Yatim, R., 2015. Prototipe Sistem Pendeteksian Awal Pencemaran Air Berbantuan Sensor Konduktivitas dan Suhu Berbasis Mikrokontroler. In: Prosiding Semnastek 2015, Seminar Nasional Sains dan Teknologi (Semnastek ke-2), Jakarta, 17 November 2015, 2015, Fakultas Teknik - UMJ: Jakarta.

[6] Mustofa, I., Goeritno, A., Prakosa, B.A., 2016. Prototipe Sistem Kontrol Berbasis Mikrokontroler untuk Pengaman terhadap Gangguan Hubung Singkat pada Otobis. In: FTI-Usakti, Seminar Nasional Teknologi Industri (SNTI) V-2016, Jakarta, $18 \mathrm{Mei}$ 2016, Fakultas Teknologi Industri - Universitas Trisakti: Jakarta. [7] Sopyandi, Goeritno, A., Yatim, R., 2016. Prototipe Sistem Pengontrolan Berbasis Payload Data Handling Berbantu Mikrokontroler Untuk Instalasi Listrik Rumah Tinggal. In: FTIUsakti, Seminar Nasional Teknologi Industri (SNTI) V-2016, Jakarta, 18 Mei 2016, Fakultas Teknologi Industri - Universitas Trisakti: Jakarta.

8] Prakoso, B.A., Goeritno, A., Prakosa, B.A., 2016. Prototipe Sistem Pengontrolan Berbasis Mikrokontroler ATmega32 untuk Analogi Smart Green House. In: FTI-Usakti, Seminar Nasional Teknologi Industri (SNTI) V-2016, Jakarta, 18 Mei 2016, Fakultas Teknologi Industri Universitas Trisakti: Jakarta.

[9] S.F. Ginting, A. Goeritno, dan R. Yatim. Kinerja Sistem Pengontrolan Berbantuan Sensor Voice Recognition dan Mikrokontroler ATmega16 untuk Pengoperasian Aktuator. In: FTI-Usakti, Seminar Nasional Teknologi Industri (SNTI) V2016, Jakarta, 18 Mei 2016, Fakultas Teknologi Industri Universitas Trisakti: Jakarta.

[10] Sholehati, M.T., Goeritno, A., 2018. Sistem Minimum Berbasis Mikrokontroler ATmega2560 sebagai Sistem Pengaman pada Analogi Lemari Penyimpanan Brankas. Jurnal Rekayasa Elektrika, 14(3), pp.158-166. http://dx.doi.org/10.17529/jre.v14i3.11649

[11] Goeritno, A., Afandi, M.Y., 2019. Modul Elektronika Berbasis Mikrokontroler sebagai Sistem Pengaman pada Mobil Terintegrasi dengan Engine Immobilizer. Jurnal Rekayasa Elektrika, 15(2), pp.75-84. http://dx.doi.org/10.17529/jre.v15i2.12872

[12] Prakoso, B.A., Goeritno, A., Prakosa, B.A., 2020. Pemanfaatan Mikrokontroler AVR untuk Pengendalian Sejumlah Parameter Fisis pada Analogi Smartgreenhouse. Jurnal Ilmiah SETRUM, 9(1), pp.52-59.

13] Goeritno, A., Pratama, S., 2020. Rancang-Bangun Prototipe Sistem Kontrol Berbasis Programmable Logic Controller untuk Pengoperasian Miniatur Penyortiran Material. Jurnal Rekayasa Elektrika, 16(3), pp.198-206. http://dx.doi.org/10.17529/jre.v16i3.14905

[14] Tirta, S., Goeritno, A., 2020. Simulator Berbasis PLC untuk Pengaturan Lalu-lintas Jalan Raya pada Perlintasan Jalur Kapal. Jurnal RESTI, 4(6), pp.1007-1016. https://doi.org/10.29207/resti.v4i6.2668

[15] Johan, A., Goeritno, A., Ritzkal. 2016. Prototipe Sistem Elektronis Berbasis Mikrokontroler Untuk Pemantauan Instalasi Listrik. In: FTI-Usakti, Seminar Nasional Teknologi Industri (SNTI) V-2016, Jakarta, 18 Mei 2016, Fakultas Teknologi Industri Universitas Trisakti: Jakarta.

[16] Asyura, S., Goeritno, A., Ritzkal. 2016. Implementasi Sensor LM35 Berbantuan Mikrokontroler untuk Pengkondisian Suhu Ruangan sebagai Upaya Penerapan Efisiensi Energi Listrik. In: FTI-Usakti, Seminar Nasional Teknologi Industri (SNTI) V- 
2016, Jakarta, 18 Mei 2016, Fakultas Teknologi Industri Universitas Trisakti: Jakarta.

[17] Goeritno, A., Ritzkal, Johan, A., 2016. Kinerja Prototipe Sistem Elektronis Berbasis Mikrokontroler Arduino UNO R3 Untuk Pemantauan Analogi Instalasi Listrik. Jurnal Ilmiah SETRUM, vol. 5, no. 2, hlm. 94-99.

[18] Hendrian, F., Ritzkal, Goeritno, A., 2017. Penggunaan Protokol Internet untuk Sistem Pemantauan pada Analogi Instalasi Listrik Fase-3 Berbantuan Mikrokontroler Arduino UNO R3 Terkendali melalui Smartphone Berbasis Android. In: SNRT ke-2 FSTUPH, Seminar Nasional Sains, Rekayasa, dan Teknologi 2017, Tangerang, 17-18 Mei 2017, Fakultas Sains dan Teknologi Universitas Pelita Harapan: Tangerang.

[19] Suhendri, Goeritno, A., 2018. Pemantauan Energi Listrik pada Satu kWH-meter Fase Tunggal untuk Empat Kelompok Beban Berbasis Metode Payload Data Handling. Jurnal Rekayasa Elektrika, 14(3), pp.189-197. http://dx.doi.org/10.17529/jre.v14i3.11952

[20] Setyawibawa, I., Goeritno, A., 2019. Communication Interface Adapter Berbasis Mikrokontroler Arduino Terkendali Sinyal Dual Tone Multi Frequency. Jurnal ELKHA (Jurnal Teknik Elektro), 11(1), pp.19-26. http://dx.doi.org/10.26418/elkha.v11i1.30374

[21] Suhartono, D., Goeritno, A., 2019. Prototipe Sistem Berbasis Mikrokontroler untuk Pengkondisian Suhu pada Analogi Panel dengan Analogi Sistem Air Conditioning. Jurnal EECCIS (Electrics, Electronics, Communications, Controls, Informatics, Systems), 13(1), pp. 22-30.

[22] Nasyarudin, A.F., Ritzkal, Goeritno, A., 2020. Prototipe Perangkat untuk Pemantauan dan Pengendalian Berbasis Web Diiintegrasikan ke Smarthome System, Indonesian Journal of Electronics and Instrumentations Systems (IJEIS), 10(2), pp.167178. https://doi.org/10.22146/ijeis.58316

[23] Fazry, H.A., Goeritno, A., 2020. Sistem Minimum dengan Battery Back-up Berbasis Mikrokontroler Arduino Untuk Pengoperasian Inkubator. Jurnal Ilmiah SETRUM, 9(2), hlm. 113-126.

[24] Masykur, F., Prasetiyowati, F. 2016. Aplikasi Rumah Pintar (Smart Home) Pengendali Peralatan Elektronik Rumah Tangga Berbasis Web. Jurnal Teknologi Informasi dan Ilmu Komputer, 3(1), pp.51-58. http://dx.doi.org/10.25126/jtiik.201631156

[25] Wibisono, S., 2017. Rancang Bangun Sistem Pengendali Jarak Jauh Radio Digital Berbasis PC. Jurnal Teknologi Informasi DINAMIKA, XII (1), pp.67-74.

[26] Goeritno, A., Hendrian, F., Ritzkal, 2017. Lampu Pijar pada Analogi Instalasi Listrik Fase-Tiga Terkendali melalui Smartphone Berbasis Android Terhubung Internet Berbantuan Mikrokontroler. In: SNATIF 2017 Fakultas Teknik UMK, Seminar Nasional Teknologi dan Informatika. Kudus, 25 Juli 2017, Fakultas Teknik UMK: Kudus.

[27] Goeritno, A., Hendrian, F., Ritzkal, 2019. Pengendalian Lampu Pijar pada Analogi Instalasi Listrik Fase-Tiga melalui
Smartphone Berbasis Android Berbantuan Jaringan Wi-Fi. Jurnal Ilmiah SETRUM, 8(2), pp.274-286.

[28] Goeritno, A., Ritzkal, Johan, A., 2016. Kinerja Prototipe Sistem Elektronis Berbasis Mikrokontroler Arduino UNO R3 Untuk Pemantauan Analogi Instalasi Listrik. Jurnal Ilmiah SETRUM, vol. 5, no. 2, hlm. 94-99.

[29] Magdalena, G., Halim, F.A., Aribowo, A., 2013. Perancangan Sistem Akses Pintu Garasi Otomatis Menggunakan Platform Android. In: CSGTEIS Universitas Udayana, Conference on Smart-Green Technology in Electrical and Information Systems. Denpasar, November 14-15, 2013, Universitas Udayana Press: Denpasar.

[30] Fitri, Setiawan, Y., 2015. Rancang Bangun Buka Tutup Pintu Pagar Rumah Menggunakan Remote Control Wireless RF315. Jurnal SISFOKOM, 4(2), pp.49-53.

[31] Syofian, A., 2016. Pengendalian Pintu Pagar Geser Menggunakan Aplikasi Smartphone Android dan Mikrokontroler Arduino melalui Bluetooth. Jurnal Teknik Elektro ITP, 5(1), pp.45-50.

[32] Kusumawardhani, A., Nurdin, S., Sari, M.S.A., 2017. Teknologi Smartphone Android dan Aplikasinya sebagai Pengendali Pintu Air Daerah Aliran Sungai (DAS). Teknika: Engineering and Sains Journal, 1(2), pp.89-94.

[33] Samsugi, S., Ardiansyah, Kastutara, D., 2018. Arduino dan Modul Wi-Fi ESP8266 sebagai Media Kendali Jarak Jauh dengan Antarmuka Berbasis Android. Jurnal TEKNOINFO, 12(1), pp.23-27.

[34] Banzi, M., 2011. Getting Started with Arduino: the Open Source Electronis Prototyping Platform, 2nd Edition. Sebastopol, CA: O'Reilly Media, pp. 17-24.

35] Durfee, W., 2011. Arduino Microcontroller Guide. Course Material. Minneapolis: University of Minnesota, October. http://www.me.umn.edu/courses/me2011/arduino/arduinoGuide .pdf.

[36] Margolis, M., 2011. Getting Started: Arduino Cookbook. $2^{\text {nd }}$ ed. Sebastopol, CA: O’Reilly Media, Inc., pp. 1-21.

[37] Barret, S.F., 2012. Arduino Microcontroller: Processing for Everyone! 2nd edition. San Rafael, CA: Morgan \& Claypool, pp. 47-50.

[38] Banzi, M., Shiloh, M., 2015. Getting Started with Arduino: the Open Source Electronis Prototyping Platform. 3rd Edition. Sebastopol, CA: Maker Media, pp. 15-22.

[39] Pindrayana, K., Borman, R.I., Prasetyo, B., Samsugi, S., 2018. Prototipe Pemandu Parkir Mobil dengan Output Suara Manusia Menggunakan Mikrokontroler Arduino UNO. CIRCUIT: Jurnal Ilmiah Pendidikan Teknik Elektro, 2(2), pp.71-82. http://dx.doi.org/10.22373/crc.v2i2.3705

[40] RemoteXY.com. (no year). Editor of Graphical Interface. [Online]. Available: https://remotexy.com/en/help/editor/ [accessed June 22, 2020]. 